\title{
ATIVIDADE ANTIFÚNGICA IN VITRO DE ÓLEOS ESSENCIAIS SOBRE Sphaceloma ampelinum
}

\author{
Régis de Oliveira Fialho ${ }^{1}$, Marli de Fátima Stradioto Papa ${ }^{2}$
}

\footnotetext{
${ }^{1}$ Mestrando em Agronomia - Faculdade de Engenharia / UNESP Ilha Solteira (SP).

${ }^{2}$ Docente do Departamento de Fitossanidade, Engenharia Rural e Solos - Faculdade de Engenharia / UNESP Ilha Solteira (SP).
}

RESUMO: O presente trabalho teve como objetivo avaliar a atividade antifúngica in vitro de dez óleos essenciais sobre o crescimento micelial e a germinação de esporos de Sphaceloma ampelinum, agente causal da antracnose da videira. Foram utilizados os óleos essenciais de uva (Vitis vinifera), tangerina (Citrus reticulata), laranja doce (Citrus aurantium), citronela (Cymbopogon winterianus), canela (Cinnamomum zeylanicum), eucalipto (Eucalyptus staigeriana), anis estrelado (Illicium verun), alecrim (Rosmarinus officinalis), cravo (Eugenia caryophyllus) e tomilho branco (Thymus vulgaris) nas concentrações de 0,3 e $1 \%$ em relação ao volume total, os quais foram incorporados em meio de cultura ou suspensão de esporos. Determinaram-se as percentagens de inibições do crescimento micelial e da germinação de esporos. Constatou-se que os óleos essenciais de canela, tomilho branco e cravo proporcionaram os melhores efeitos de inibição sobre o crescimento micelial e a germinação de esporos de S. ampelinum e merecem mais estudos, para comprovação de sua eficiência em condições de campo.

Palavras-chave: Vitis spp. Elsinoe ampelina. Controle alternativo. Antracnose. Inibição do crescimento micelial. Inibição da germinação de esporos.

\section{ANTIFUNGAL ACTIVITY IN VITRO OF ESSENTIAL OILS ON Sphaceloma ampelinum}

\begin{abstract}
This study aimed to evaluate the in vitro antifungal activity of ten essential oils on mycelial growth and spore germination of Sphaceloma ampelinum, the causal agent of grapevine anthracnose. Essential oils of grape (Vitis vinifera), tangerine (Citrus reticulata), sweet orange (Citrus aurantium), citronella (Cymbopogon winterianus), cinnamon (Cinnamomum zeylanicum), eucalyptus staigeriana (Eucalyptus staigeriana), anis (Illicium verun), rosemary (Rosmarinus officinalis), clove (Eugenia caryophyllus) and white thyme (Thymus vulgaris) were tested at concentrations of 0,3 and $1 \%$ from the total volume, which were incorporated into the culture medium or added to the suspension. Mycelial growth and spore germination inhibition percentages were determined. Cinnamon, white thyme and clove essential oils provided the higher inhibitory effects on mycelial growth and spore germination of $S$. ampelinum. Further studies should be realized to prove its effectiveness under field conditions.
\end{abstract}

Key words: Vitis spp. Elsinoe ampelina. Alternative control. Anthracnose. Inhibition of Cultura Agronômica, Ilha Solteira, v.24, n.1, p.63-70, 2015 
mycelial growth. Inhibition of spore germination.

\section{INTRODUÇÃO}

A videira (Vitis spp.) é uma planta frutífera amplamente cultivada em todo o mundo. Tratando-se de produção, as regiões em que se cultiva a videira frequentemente enfrentam dificuldades quanto a problemas de doenças. A antracnose também conhecida como varíola ou "olho-de-passarinho", causada pelo fungo Elsinoe ampelina (de Bary) Schear, forma assexuada de Sphaceloma ampelinum de Bary, é uma das mais importantes doenças da videira. Esta doença é originária da Europa e ocorre em todas as regiões vitícolas do mundo. No Brasil, a doença começou a surgir após a introdução da cultivar Isabel e de outras cultivares americanas, procedentes do Hemisfério Norte (SOUSA; PINHEIRO, 1996). Seu controle envolve a adoção de medidas culturais, química e genética (AMORIM; KUNIYUKI, 2005).

Devido à crescente preocupação com o meio ambiente e a saúde humana, e visando a produção de alimentos de melhor qualidade, vem sendo estudada técnica alternativa de controle de doenças de plantas com a utilização de óleos essenciais. Vários estudos comprovam o efeito de óleos essenciais extraídos de plantas, que atuam como fungicidas naturais inibindo a atividade de uma gama de fungos (PEREIRA et al., 2006; ARAUJO NETO et al., 2012; RIBEIRO et al., 2013). Estes atuam tanto pela ação fungitóxica direta, inibindo o crescimento micelial e a germinação de esporos, quanto pela indução de fitoalexinas, indicando a presença de composto(s) com característica(s) de elicitor(es) (STANGARLIN et al., 1999; SALGADO et al., 2003; BRUM et al., 2012; BIGATON et al., 2013).

Este trabalho objetivou avaliar a atividade antifúngica in vitro de dez óleos essenciais sobre o fungo $S$. ampelinum, por meio de determinações das inibições do crescimento micelial e da germinação de esporos.

\section{MATERIAL E MÉTODOS}

O trabalho foi desenvolvido no Laboratório de Doenças de Plantas, da Faculdade de Engenharia - FE, Câmpus de Ilha Solteira, da Universidade Estadual Paulista "Júlio de Mesquita Filho" - UNESP, em Ilha Solteira, SP.

Foram utilizados óleos essenciais obtidos de semente de uva (Vitis vinifera), casca dos frutos de tangerina (Citrus reticulata) e de laranja doce (Citrus aurantium), folhas de citronela (Cymbopogon winterianus), canela (Cinnamomum zeylanicum), eucalipto (Eucalyptus staigeriana), alecrim (Rosmarinus officinalis) e cravo (Eugenia caryophyllus), frutos e sementes de anis (Illicium verun), e flores e folhas de tomilho branco (Thymus vulgaris), adquiridos da Ferquima Ind. e Com. Ltda.

Foi obtido um isolado de $S$. ampelinum da Micoteca da Estação Experimental de Viticultura Tropical (EEVT/EMBRAPA), no município de Jales, SP. Este foi mantido em 
tubos de ensaio com solução salina e discos de meio de cultura mais crescimento fúngico (CASTELLANI, 1939) e conservado a $11^{\circ} \mathrm{C}$ em refrigerador.

A atividade antifúngica dos óleos essenciais foi avaliada por meio da determinação das inibições do crescimento micelial e da germinação de esporos do patógeno relatados a seguir.

Determinação da inibição do crescimento micelial: Em placas de Petri contendo BDA foi repicada a cultura de $\mathrm{S}$. ampelinum que foi mantida em solução salina. Estas placas foram mantidas em estufas incubadoras a $25^{\circ} \mathrm{C}$, durante sete dias no escuro. Após esse período, foram cortados discos com $7 \mathrm{~mm}$ de diâmetro, dos bordos da cultura, os quais foram transferidos para placas de Petri, contendo o meio de cultura BDA mais óleo essencial a ser avaliado.

Foram utilizadas as concentrações de 0,3 e 1\% para cada óleo essencial, os quais foram incorporados ao meio BDA fundente, e em seguida vertido em placa de Petri de $9 \mathrm{~cm}$ de diâmetro. Para o centro de cada placa de Petri contendo meio BDA apenas, para o tratamento testemunha, e BDA mais óleo essencial, foi transferido um disco de BDA com o crescimento micelial de $S$. ampelinum. As placas foram incubadas à temperatura de $25^{\circ} \mathrm{C}$, sem fotoperíodo durante sete dias. As avaliações foram realizadas durante sete dias, medindo-se o diâmetro do crescimento micelial, em duas posições perpendiculares por placa, calculando-se em seguida as médias. Este ensaio foi realizado duas vezes e foi realizada uma análise conjunta de variância dos dados na análise estatística.

Determinação da inibição da germinação dos esporos: Para a produção de esporos foi realizado procedimento semelhante ao usado na obtenção da colônia fúngica. Foram utilizadas as concentrações de 0,3 e 1\% para cada óleo essencial. A suspensão de esporos utilizada foi obtida adicionando-se $10 \mathrm{~mL}$ de água destilada esterilizada a placa de Petri contendo a colônia fúngica, liberando-se os esporos para a água com o auxilio de um pincel. A suspensão de esporos foi filtrada em gaze dupla e sua concentração foi determinada com auxilio de hemacitômetro e ajustada para a concentração de 2 x $10^{4}$ esporos/mL. Para verificar o efeito dos óleos na germinação de esporos foram preparadas soluções padrão contendo as concentrações dos óleos a serem analisados e a suspensão de esporos. Destas soluções padrões alíquotas de $80 \mu \mathrm{L}$ foram pipetados para as células de placa Elisa e estas foram mantidas a $25^{\circ} \mathrm{C}$, sem fotoperíodo durante 9 horas. Ao término deste período, procedeu-se à interrupção do processo germinativo utilizando-se uma gota de lactoglicerol em cada célula da placa Elisa. Como testemunha utilizou-se apenas água destilada esterilizada. Em microscópio ótico realizou-se a contagem de 100 esporos em cada célula, separando-os em esporos germinados e não germinados. Como esporo germinado foi considerado o esporo que apresentou tubo germinativo igual ou maior que a sua largura. Este ensaio foi realizado duas vezes e foi realizada uma análise conjunta de variância dos dados na análise estatística.

Nos dois ensaios realizados, o delineamento experimental foi inteiramente casualizado, seguindo o esquema fatorial $10 \times 2$ (óleos essenciais x concentrações) e um tratamento testemunha (apenas BDA ou água destilada esterilizada) totalizando 21 
tratamentos e cinco repetições por tratamento. Cada repetição foi constituída por uma placa de Petri ou uma célula da placa de ELISA

A partir dos dados obtidos determinaram-se as percentagens de inibições do crescimento micelial (PIC) e da germinação de esporos (PIG) por meio das fórmulas apresentadas a seguir, para cada tratamento, em relação ao tratamento testemunha.

$\mathrm{PIC}=[($ diâmetro da testemunha - diâmetro do tratamento $) /$ diâmetro da testemunha $] \times 100$

PIG $=[$ (germinação da testemunha - germinação do tratamento $) /$ germinação da testemunha]x 100

Os dados de PIC e PIG foram submetidos à análise conjunta e as médias, comparadas pelo teste de Tukey a $5 \%$ de probabilidade, sendo esta realizada utilizando-se o programa SISVAR.

\section{RESULTADOS E DISCUSSÃO}

Vários trabalhos têm mostrado que óleos essenciais apresentam efeito sobre fitopatógenos in vitro (ZAMBONELLI et al., 1996; CIMANGA, 2002; DINIZ et al., 2003; ABREU, 2006; PARET et al., 2010; SOUSA et al., 2012; SANTOS et al., 2013), contudo não foram encontradas informações de trabalhos envolvendo os óleos essenciais utilizados nestes experimentos e $S$. ampelinum.

A análise conjunta de variância PIC e PIG permitiu observar que não houve diferença significativa entre os experimentos (Tabela 1). Assim como não foram significativas as interações envolvendo os experimentos. Observa-se que os fatores doses x tratamentos, apresentaram interação significativa tanto para PIC quanto para PIG (Tabela 1).

Tabela 1. Resumo da análise de variância conjunta para os dois experimentos utilizados para determinar a percentagem inibição do crescimento micelial (PIC) e a percentagem da inibição da germinação de esporos (PIG) de Sphaceloma ampelinum. Ilha Solteira, SP. 2010 .

\begin{tabular}{lccc}
\hline & & PIC & PIG \\
\cline { 3 - 4 } Fontes de Variação & G.L. & Q.M. & Q.M. \\
\hline Experimentos & 1 & 0.0200 & 0.0003 \\
Tratamentos & 9 & $30453.6444^{* *}$ & $263.5168^{* *}$ \\
Doses & 1 & $612.5000^{* *}$ & $64.1504^{* *}$ \\
Experimentos x tratamentos & 9 & 0.4088 & 0.0223 \\
Experimentos x dose & 1 & 0.3200 & 0.0772 \\
Doses x tratamentos & 9 & $617.4888^{* *}$ & $8.8079^{* *}$ \\
Doses x tratamentos x experimentos & 9 & 0.1533 & 0.0137 \\
Resíduo & 160 & 51.0182 & 3.7951 \\
\hline TOTAL & 199 & & \\
\hline Média geral & \multicolumn{3}{c}{67,64} \\
CV $(\%)$ & \multicolumn{3}{c}{8,42} \\
\hline
\end{tabular}

** Significativo a 5\% de probabilidade pelo teste $\mathrm{F}$

Os dez óleos essenciais avaliados nas concentrações de 0,3 e 1\% (Tabela 2) 
proporcionaram percentagens de inibição do crescimento micelial (PIC) de S. ampelinum que variaram de 0,5 a 100\%. Nas duas concentrações avaliadas, os óleos essenciais de eucalipto, citronela, canela, tomilho branco e cravo não diferiram significativamente entre si, ao nível de $5 \%$ de probabilidade e proporcionaram as maiores PIC, variando entre 81 a $100 \%$ de inibição. O óleo essencial de anis estrelado na concentração de $1 \%$ proporcionou PIC de $89 \%$ e não diferiu estatisticamente dos óleos essenciais de eucalipto, citronela, canela, tomilho branco e cravo, sendo os mais eficientes. Para os óleos essenciais de uva, tangerina, laranja doce, alecrim, e anis estrelado, na menor concentração - 0,3\%, foram obtidas as menores PIC, as quais diferiram dos óleos essenciais mencionados anteriormente e variaram de 0,5 a $66 \%$. Houve interação significativa entre as contrações dos óleos essenciais de tangerina, anis estrelado, citronela e eucalipto a 5\% de probabilidade. Estes óleos apresentaram correlação positiva entre concentração e a PIC, ou seja, quanto maior a concentração, maior a PIC.

Quanto ao efeito dos óleos essenciais sobre a percentagem de inibição da germinação (PIG) dos esporos de S. ampelinum (Tabela 2), destacaram-se os óleos essenciais de eucalipto, citronela, tangerina, canela, laranja doce, tomilho branco e cravo como os melhores na inibição da germinação dos esporos, nas duas concentrações. Na concentração de $0,3 \%$ os óleos essenciais de uva, anis estrelado, alecrim e citronela proporcionaram as menores PIG e diferiram dos outros seis óleos essenciais. Na concentração de $1 \%$ apenas o óleo essencial de alecrim diferiu dos nove óleos essenciais e foi obtida a menor PIG (89\%). Não houve significância entre as concentrações para todos os óleos essenciais, com exceção dos óleos essenciais de alecrim e uva. Para estes óleos observa-se que a medida que a concentração do óleo essencial é aumentada, a PIG também aumenta.

Tabela 2. Percentagem de inibição do crescimento micelial (PIC) e da germinação de esporos (PIG) de Sphaceloma ampelinum por dez óleos essenciais. Ilha Solteira, SP. 2010.

\begin{tabular}{|c|c|c|c|c|}
\hline \multirow{3}{*}{ Óleos essenciais } & \multicolumn{2}{|c|}{ PIC } & \multicolumn{2}{|c|}{ PIG } \\
\hline & \multicolumn{2}{|c|}{ Concentração - \% } & \multicolumn{2}{|c|}{ Concentração - \% } \\
\hline & 0,3 & 1,0 & 0,3 & 1,0 \\
\hline Uva & $0,5 \mathrm{fA}^{1}$ & $0,7 \mathrm{cA}$ & $94 \mathrm{bA}$ & $96 \mathrm{abB}$ \\
\hline Eucalipto & 86 aA & $100 \mathrm{aB}$ & 99 aA & $100 \mathrm{aA}$ \\
\hline Citronela & $81 \mathrm{abA}$ & $100 \mathrm{aB}$ & $98 \mathrm{abA}$ & $99 \mathrm{aA}$ \\
\hline Tangerina & $27 \mathrm{cdA}$ & $49 \mathrm{bB}$ & $99 \mathrm{aA}$ & $100 \mathrm{aA}$ \\
\hline Canela & $100 \mathrm{aA}$ & $100 \mathrm{aA}$ & $100 \mathrm{aA}$ & $100 \mathrm{aA}$ \\
\hline Laranja doce & $33 \mathrm{de} A$ & $40 \mathrm{bA}$ & $99 \mathrm{aA}$ & $100 \mathrm{aA}$ \\
\hline Tomilho branco & $100 \mathrm{aA}$ & $100 \mathrm{aA}$ & $100 \mathrm{aA}$ & $100 \mathrm{aA}$ \\
\hline Cravo & $100 \mathrm{aA}$ & $100 \mathrm{aA}$ & $100 \mathrm{aA}$ & $100 \mathrm{aA}$ \\
\hline Anis estrelado & $66 \mathrm{bcA}$ & $89 \mathrm{aB}$ & $95 \mathrm{bA}$ & $97 \mathrm{abA}$ \\
\hline Alecrim & 17 efA & $19 \mathrm{bcA}$ & $86 \mathrm{cA}$ & $89 \mathrm{cB}$ \\
\hline CV\% & \multicolumn{2}{|c|}{8,42} & \multicolumn{2}{|c|}{1,89} \\
\hline
\end{tabular}

${ }^{1}$ Letras minúsculas diferentes, na coluna, e letras maiúsculas diferentes, na linha para PIC ou PIG, indicam diferença pelo teste de Tukey a $5 \%$.

Os óleos essenciais proporcionaram mais inibições sobre os esporos de S. ampelinum do que sobre o crescimento micelial. Isto pode ter ocorrido pela maior sensibilidade do

Cultura Agronômica, Ilha Solteira, v.24, n.1, p.63-70, 2015 
esporo ou exposição dos mesmos, uma vez que os esporos permanecem imersos na água mais óleo essencial. O crescimento micelial se desenvolve sobre o meio de cultura, que contem o óleo essencial, e com isso, tem menor exposição e se desenvolveu melhor. Em outros trabalhos também se encontraram estes resultados (SILVA et al., 2009; LIMA et al., 2010; PIATI et al., 2011). Segundo French (1992), na natureza, a difusão de traços de compostos voláteis pode induzir ou inibir a germinação ou o crescimento, ou desencadear alterações no desenvolvimento em plantas e fungos.

Segundo Teuscher (1990), a exploração da atividade biológica de compostos secundários presentes no extrato bruto ou óleos essenciais de plantas pode se constituir, ao lado da indução de resistência, em mais uma forma potencial de controle alternativo de doenças em plantas cultivadas. O presente trabalho confirma a afirmação do autor e ressaltase que há necessidade de avaliações em condições de campo para comprovação de eficiência. Considerando as inibições da germinação de esporos e do crescimento micelial, os óleos essenciais de canela, tomilho branco e cravo apresentaram-se como os óleos com maiores atividades atifúngicas e merecem mais estudos.

\section{CONCLUSÕES}

- Todos os 10 óleos essenciais testados têm maior atividade antifúngica sobre os esporos de Sphaceloma ampelinum do que sobre o crescimento micelial.

- Sobre a inibição do crescimento micelial, os óleos essenciais de eucalipto, citronela, canela, tomilho branco e cravo foram os mais eficientes.

- Sobre a inibição da germinação de esporos, os óleos essenciais de eucalipto, citronela, tangerina, canela, laranja doce, tomilho branco e cravo foram os mais eficientes.

- Considerando o efeito in vitro sobre as inibições do crescimento micelial e da germinação de esporos de Sphaceloma ampelinum, os óleos essenciais de canela, tomilho branco e cravo são mais eficientes sobre Sphaceloma, merecendo mais estudos para a determinação de suas eficiências no controle da antracnose da videira.

\section{REFERÊNCIAS BIBLIOGRÁFICAS}

ABREU, C. L. M. Controle de Alternaria solani em tomateiro (Lycopersicon esculentum) com óleos essenciais. 2006. 71 f. Tese (Doutorado em Agronomia Horticultura) - Faculdade Ciências Agronômicas, Universidade Estadual Paulista, Botucatu, 2006.

AMORIM, L.; KUNIYUKI, H. Doenças da videira (Vitis spp.). In: KIMATI, H.; AMORIM, L.; REZENDE, J. A. M.; BERGAMIN FILHO, A.; CAMARGO, L. E. A. (Org.). Manual de Fitopatologia: doenças das plantas cultivadas. São Paulo: Agronômica Ceres, 2005. cap. 70, p. 639-651.

Cultura Agronômica, Ilha Solteira, v.24, n.1, p.63-70, 2015 
ARAUJO NETO, A. C.; ARAUJO, P. C.; SOUZA, W. C. O.; MEDEIROS, J. G. F.; AGUIAR, A. V. M. Óleo essencial de anis na incidência e controle de patógenos em sementes de erva-doce (Foeniculum vulgare mill.). Revista Verde, Mossoró, v. 7, n. 1, p.170-176, 2012.

BIGATON, D.; BACCHI, L. M. A.; FORMAGIO, A. S. N.; GAVASSONI, W. L.; ZANELLA, C. S. Avaliação da atividade fungicida de extratos e óleos essenciais sobre ferrugem asiática da soja. Revista Ciência Agronômica, Fortaleza, v. 44, n. 4, p.757-763, 2013.

BRUM, S. R. B. C. Efeito de óleos essenciais no controle de fungos fitopatogênicos. 2012. 135 f. Dissertação (Mestrado em Produção Vegetal) - Câmpus Universitário de Gurupi, Universidade Federal do Tocantins, Gurupi, 2012.

CASTELLANI, A. Viability of some pathogenic fungi in distilled water. Journal of Tropical Medicine Hygiene, London, v. 42, n. 3, p.225, 1939.

CIMANGA, K.; APERS, S.; BRUYNE, T.; VAN MIERT, S.; HERMANS, N.; TOTTÉ, J.; PIETERS, L.; VLIETINCK, A. J.; KAMBU, K.; TONA, L. Chemical composition and antifungal activity of essential oils of some aromatic plants growing in the Democratic Republic of Congo. Journal of Essential Oil Research, Carol Stream, v. 14, n. 5, p.382$387,2002$.

DINIZ, S. P. S. S.; UTUMI, H.; BONZANINI, F.; QUEIROZ, M. C. Controle do fungo Myrothecium verrucaia por óleos essenciais. Revista Brasileira de Plantas Medicinais, Botucatu, v. 6, n. 1, p.60-62, 2003.

FRENCH, R. C. Volatile chemical germination stimulators of rust and other fungal spores. Mycologia, Bronx, v. 84, n. 3, p.277-288, 1992.

LIMA, W. G.; MELO FILHO, P. A.; CÂMARA, M. P. S.; SANTOS, R. C.; CÂMARA, C. A. G.; SILVA, A. M.; SILVA; A. M. F.; GARCIA, A. L.; BEZERRA, C. S. Efeito de óleos vegetais no controle de Colletotrichum gossypii var. cephalosporioides. 2010. Artigo em Hypertexto. Disponível em: <http://www.infobibos.com/Artigos/2010_3/OleosVegetais/index.htm>. Acesso em: 16 set. 2013.

PEREIRA, M. C.; VILELA, G. R.; COSTA, L. M. A. S.; SILVA, R. F.; FERNANDES, A. F.; FONSECA, E. W. N.; PICCOLI, R. H. Inibição do desenvolvimento fúngico através da utilização de óleos essenciais de condimentos. Ciência e Agrotecnologia, Lavras, v. 30, n. 4, p.731-738, 2006.

Cultura Agronômica, Ilha Solteira, v.24, n.1, p.63-70, 2015 
PARET, M. L.; CABOS. R.; KRATKY, B. A.; ALVAREZ, A. M. Effect of plant essential oils on Ralstonia solanacearum race 4 and bacterial wilt of edible ginger. Plant Disease, Saint Paul, v. 94, n. 5, p.521-527. 2010.

PIATI, A.; SCHNEIDER, C. F.; NOZAKI, M. H. Efeito in vitro do óleo essencial de Eucalyptus globulus sobre o crescimento e desenvolvimento de Penicillium sp. Semina: Ciências Agrárias, Londrina, v. 32, n. 3, p.1033-1040, 2011.

RIBEIRO, M. C. V.; PEREIRA, T. S.; PEREIRA, R. B.; VIDAL, M. C.; PINHEIRO, J. B. Óleos essenciais no controle do oídio em pimentao. In: JORNADA CIENTÍFICA DA EMBRAPA HORTALIÇAS, 3., 2013, Brasília. Anais... Brasília: Embrapa Hortaliças, 2013. CD-ROM.

SALGADO, A. P. S; CARDOSO, M. G.; SOUZA, P. E.; SOUZA, J. A.; ABREU, C. M. P; PINTO, J. E. B. P. Avaliação da atividade fungitóxica de óleos essenciais de folhas de Eucalyptus sobre Fusarium oxysporum, Botrytis cinerea e Bipolaris sorokiniana. Ciência Agrotécnologia, Lavras, v. 27, n. 2, p.249-254, 2003.

SANTOS, G. R.; BRUM, R. B. C. S.; CASTRO, H. G.; CONÇALVES, C. G.; FIDELIS, R. R. Effect of essential oils of medicinal plants on leaf blotch in Tanzania grass. Revista Ciência Agronômica, Fortaleza, v. 44, n. 3, p.587-593, 2013.

SILVA, A. D.; SALES, N. D. L. P.; ARAUJO, A. V.; CALDEIRA JÚNIOR, C. F. Efeito in vitro de compostos de plantas sobre o fungo Colletotrichum gloeosporioides Penz. isolado do maracujazeiro. Ciência e Agrotecnologia, Lavras, v. 33, edição especial, p.1853-1860, 2009.

SOUSA, J. S. I.; PINHEIRO, E. D. Pragas e moléstias. In: SOUSA, J. S. I. Uvas para o Brasil. 2. ed. Piracicaba: FEALQ, 1996. cap. 13, p. 609-727.

SOUSA, R. M. S.; SERRA, I. M. R. S; MELO, T. A. Efeito de óleos essenciais como alternativa no controle de Colletotrichum gloeosporioides, em pimenta. Summa Phytopathologica, Botucatu, v. 38, n. 1, p.42-47, 2012.

STANGARLIN, J. R.; SCHWAN-ESTRADA, K. R. F.; CRUZ, M. E. S.; NOZAKI, M. H. Plantas medicinais e controle alternativo de fitopatógenos. Revista Biotecnologia Ciência \& Desenvolvimento, Brasília, v. 2, n. 11, p.16-21, 1999.

TEUSCHER, E. Pharmazeutische biologie. Braunschweig/Wiesbaden: Vieweg, 1990. 664 p.

ZAMBONELli, A.; D'AULERIO, A. Z.; BIANCHI, A.; ALBASINI, A. Effects of essential oils on phytopathogenic fungi in vitro. Journal of Phytopathology, Berlin, v. 144, n. 3, p.491-494, 1996. 